11. Коробов, В. И. Василий Шукшин. - Москва : Современник, 1984. - 286 с. - (Библиотека «Любителям российской словесности»).

12. Ямпольский, М. Демон и Лабиринт. (Диаграммы, деформации, мемесис). - Москва : Нов. лит. обозрение, 1996. - 325 с.

13. Белая, Г. А. Художественный мир современной прозы. - Москва : Наука, 1983. - 191 с. - Из содерж.: Парадоксы и открытия В. Шукшина. - С. 93-118.

14. Панченко, А. М. Смех как зрелище // Смех в Древней Руси / Д. С. Лихачёв, А. М. Панченко, Н. В. Понырко. - Ленинград : Наука, 1984. - 75-153.

15. Уракова, А. П. Поэтика тела в рассказах Эдгара Аллана По. - Москва : ИМЛИ РАН, 2009. - 259 с.

Evgenia A. Moskovkina, Ph. D. in Philology, Associate Professor Altai State Institute of Culture (Barnaul, Russia) evgenya.moskovkina@yandex.ru

\title{
BODY POETICS IN VASILY SHUKSHIN'S PROSE
}

Abstract. Combination of cinematographic and poetological literary techniques on creating an artistic image is a style-forming means in Vasily Shukshin's prose. Vasily Shukshin reaches a remarkable synergetic effect through the use his own actor, a director, a writer's experience that, from the one side, well prepares any piece of text wrote by him to screen adaptation and, from the other side, makes his screenplays deeply literary. Vasily Shukshin being author of two unique genres ("novel for theatre" and "movie-essay") brings an element of theatrical plastic art, scenic clearness, body expression into his each literary writing. Dramatis personae of Vasily Shukshin's writings meaningfully "speak with their body" - it's when not only mimics but also body dynamics and energy arrange a characters' subcomponents.

Keywords: Vasily Shukshin's prose, a pattern, an image, literary technique, a body, poetics, psychologism, psychopoetics.

УДК 725.821:008(571.54)

DOI: 10.32340/2414-9101-2019-4-14-19

В. В. Некрашевич

Восточно-Сибирский государственный институт культуры (Улан-Удэ, Россия) vinek17@mail.ru

\section{ДРАМАТИЧЕСКИЙ ТЕАТР КАК ЧАСТЬ ИСТОРИКО-КУЛЬТУРНОГО НАСЛЕДИЯ РЕСПУБЛИКИ БУРЯТИЯ}

Аннотация. Представлен краткий обзор истории развития любительского театрального творчества и профессионального театрального искусства в дореволюционной, советской и постсоветской Бурятии. Раскрыта специфика научного подхода к пониманию театрального наследия как историко-культурного феномена. На примере деятельности Государственного русского драматического театра им. Н. А. Бестужева (г. Улан-Удэ, Республика Бурятия, Россия) - первого профессионального театра Бурятии (основан в 1928 г.) - автор характеризует конституирующую роль художественно-эстетических традиций театрального творчества в отношении регионального культурного процесса.

Ключевые слова: региональный культурный прочесс, нематериальное историко-культурное наследие, культурное пространство региона, театральное искусство, драматический театр, сохранение театрального наследия, воспроизводство художественной культуры, Государственный русский драматический театр им. Н. А. Бестужева, Бурятия.

В начале XXI века Россия столкнулась с тревожными реалиями современности и проблемами культуры, ставшими знаковым явлением. Тяжёлые, а порой даже катастрофические, перемены коснулись всех сфер жизни, в том числе и духовного развития, следовательно, решение этих вопросов представляет на сегодняшний момент самую главную цель для нашего государства.

Определение феномена культуры неотделимо от человеческой деятельности, так как культура является её результатом. Это определено историческим развитием человека и мирового сообщества, связанным со сменой культур, характерных для различных типов обществ, между которыми сущест- 
вует преемственность. Природа и культура в своей совокупности образуют среду обитания человека. В культурологии эта особая среда определяется как культурное пространство. Навыки и знания, приобретённые человечеством от начала времён, накапливаются и приумножаются на протяжении столетий, образуя культурное наследие - важную часть жизни и культуры каждого народа. Таким образом, культурное наследие создаётся человеком в процессе освоения им среды обитания. В культурном пространстве аккумулируется вся совокупность историко-культурного наследия, в котором самым наглядным образом отражается многогранная история человечества, а культура является преобразователем ценностей и норм и гарантом связи поколений.

Единое определение историко-культурного наследия пока не выработано, так как данный термин рассматривается с разных научных подходов. Так, история изучает культурное наследие, прежде всего, как источник информации о развитии и становлении современного общества. Объекты культурного наследия для историков это неопровержимые доказательства существования тех или иных людей и событий, своеобразные гаранты достоверности, не позволяющие ей (истории) искажаться.

С точки зрения культурологии культурное наследие это один из основных способов существования культуры. Доктор культурологии Э. А. Шулепова полагает, что «наследие, по сути, выступает как макрообъект, который позволяет судить о «следах» прошлого в настоящем культурной среды» [1, с. 9]. По мнению доктора философии Л. В. Баевой «культурное наследие во многом, определяется как воплощение традиции, передача которой способствует наделению смыслом прошлого и настоящего» [2, с. 109]. А. В. Любичанковский характеризует культурное наследие как «отнесённые к определённому пространству и времени типичные и уникальные образцы всех сторон материальной и духовной деятельности населения» [3, с. 85]. А. А. Копсергенова считает, что «культурное наследие проявляется в ценностях прошлого, сохраняемых и транслируемых последующими поколениями в качестве основополагающих» [4, с. 7]. Из этого следует, что культурологи и философы культуры рассматривают культурное наследие как своего рода «архив» или «библиотеку», в которых хранятся все полезные знания, которые могут быть использованы и усовершенствованы обществом в настоящем и будущем, кроме того, наследие наглядно демонстрирует достижения человеческой мысли. Именно культурологический и исторический подходы наиболее полно определяют степень информативности и востребованности того или иного объекта, обозначают критерии его отбора и его способность влиять на общество.

Юридическая точка зрения не учитывает эмоциональную и информационную ценность наследия, но обеспечивает защиту культурного и природного достояния человечества на законодательном уровне. Опираясь на законы государство, имеет возможность выполнять обязательства по сохранению историко-культурного и природного наследия, реализуя всю совокупность практических мероприятий, решений и действий в этой сфере всеми существующими в культурном пространстве социальными и социокультурными институтами, учреждениями культуры и каналами массовой коммуникации.

Если объединить эти подходы, то культурное наследие можно определить как совокупность материальных и нематериальных ценностей, созданных человеком на протяжении предыдущих исторических эпох, защищённых от забвения процессами преемственности и от разрушения законодательными актами. Исходя из того, что жизнь современного человеческого сообщества характеризуется наличием различных форм человеческой деятельности, а также значительным диапазоном культур и ценностей, нематериальное культурное наследие включает в себя целый комплекс самых разнообразных культурных форм, отражающих сложное и многогранное развитие человечества. Ценностные основы, нормативные образцы, нравственные принципы, религиозные верования, философские воззрения, научные взгляды, политическая культура, различного уровня общности, объединённые по этническим, национальным, региональным и прочим признакам, составляют основу нематериального историко-культурного наследия.

Объективная картина историко-культурного наследия не может быть создана без анализа театрального процесса. Театр является одним из важных элементов мирового культурного наследия. Все социокультурные изменения, происходившие в обществе, наглядно прослеживаются в истории развития театра, поскольку театр служит в культурном пространстве каналом трансляции ценностей и норм, выработанных культурой, в виде художественных образов, жизненных ориентиров, моральных установок. Культурное пространство, вбирающее в себя традиции, ценностные ориентиры, нормативные образцы поведения и т. д., характерные для конкретного этапа развития общества, находит своё отражение в творческой деятельности театра, который, в свою очередь, символизирует идеальные устремления социума данного культурного пространства. Тем самым можно утверждать, что 
театр является своего рода отпечатком духовного развития человека в культурном пространстве. Культурное пространство, в свою очередь, представляет собой своеобразный «накопитель» культурных артефактов и явлений - элементов массива историко-культурного наследия.

Мировое наследие театра колоссально, оно всегда освещало нравственные и этические темы, которые формировали идеалы и культурные ценности человечества, поскольку театр на любом этапе своего развития не существовал сам по себе, изолированно от других явлений культуры. Что касается, истоков русского театра, то они глубоко национальны, театральное действие выросло на исконно русской культурной почве, хотя и подверглось иностранным влияниям. Начало русским театральным традициям положило народное творчество и, прежде всего, обряды, праздники, связанные с трудовой деятельностью. Характер русского театра всегда был глубоко патриотичен, он играл ведущую роль в нравственном возрождении нации. Новой ступенью в истории русского театрального искусства явился советский театр, возникший после Октябрьской революции. В целом феномен советского репертуарного театра не имеет аналогов при других общественных устройствах. Театр стал не только средством нравственного развития общества, но и проводником государственной идеологии. Культурная политика советского государства способствовала воспитанию массового зрителя, видевшего в театральном творчестве эстетический идеал и источник информации, сведений по литературе, искусству, истории, этике, культуре поведения.

Культурное пространство России сформировано исторически определившимися регионами, в которых сосуществуют культуры разных народов. На территории каждого региона столетиями складывалось самобытное культурное пространство, специфику которого определяли природные условия, историческое своеобразие социальных, этнокультурных, религиозных особенностей, а также индивидуальные признаки культурного, политического и экономического развития. Республика Бурятия является одним из таких регионов.

Республика Бурятия представляет собой уникальный регион России, где веками совместно проживают эвенки, буряты, русские, представители иных национальностей. На этой территории сосуществуют шаманизм, буддизм, христианство и иные конфессии, развиваются культурные традиции как Востока, так и Запада. Более 60 национальностей и народностей, проживающих на территории Бурятии, сохранили родной язык, культурные традиции своего народа, художественные ремесла и фольклор. Бережное отношение к своим корням позволило сохранить удивительный мир народного искусства бурятского региона, включающий в себя и памятники материальной культуры, и богатое духовное наследие. Потому сегодня республика имеет богатое культурное разнообразие и существенным её достижением является то, что, вопреки сложным экономическим и социальным проблемам в обществе, мы смогли сберечь все самое важное, составляющее сегодня фундамент современной бурятской культуры. В республике успешно работают 37 государственных учреждений культуры и искусства, различные творческие союзы, общественные объединения и более тысячи муниципальных культурно-досуговых организаций. Республика обладает богатой историей, поэтому здесь во многих населённых пунктах имеются архитектурно-исторические памятники. В фондах и выставочных залах музеев хранятся наиболее уникальные образцы материальной культуры.

Культурное пространство Бурятии находится в постоянном движении и развитии, оно непрерывно пополняется и обогащается новыми достижениями, но при этом оно сохраняет наследие прошлых эпох. Бурятия характеризуется как исторически значимое культурное пространство сосуществования кочевой азиатской и оседлой славянской культур.

История Русского драматического театра в Бурятии имела совершенно особую специфику, несмотря на то, что его становлению были свойственны, пожалуй, все те трудности формирования и творческие перипетии, через которые прошли многие российские провинциальные театры. Именно его деятельность стала тем фундаментом, который подготовил зрителей к серьёзному восприятию театрального искусства.

Факторы, повлиявшие на развитие художественной культуры Бурятии в целом, и театральной жизни в частности, в дореволюционный период, являются отражением основных тенденций социкультурных процессов России. Так, Е. С. Манзырева полагает, что «динамика художественной культуры в городах Восточной Сибири XIX - начала XX вв. носила волнообразный характер и происходила импульсами... первая волна связана с появлением в регионе во второй четверти XIX в. политических ссыльных (участников декабрьских и польских восстаний); вторая волна, охватывающая середину и вторую половину XIX в., связана с активизацией деятельности местных творческих сил (преимущественно из среды купечества, а так же представителей разных чинов); третья волна затронула 
конец XIX в. - первую четверть XX в. и была связана с проведением железной дороги, способствовавшим притоку в регион «свежих» сил, идей и новаций» [5, с. 89-90].

Предыстория Русского драматического театра - свидетельство того, как на протяжении XIX века в Забайкалье зарождались и развивались прогрессивные идеи и начинания демократической интеллигенции. «Искусству театра в эстетической программе декабристы уделяли большое внимание. Они видели в нем важнейшее средство духовного воздействия на общество» [6, с. 161]. Логичным результатом просветительской деятельности декабристов и других политических ссыльных в городах Кяхта, Нерчинск, Верхнеудинск стало возникновение любительского театра. Его отличительным свойством было то, что он не походил на буржуазно-обывательские затеи и увеселения. Коммерческий подход к искусству здесь отсутствовал, доходы от спектаклей шли на постройку учебных заведений, в пользу музеев, библиотек, больниц, на издание газет.

Но лишь после октябрьских событий 1917 года были созданы все условия для приобщения народа к просвещению и мировой культуре. События культурной жизни Бурятии 1918-1928-х годов подтвердили жизненность реалистических традиций русского театра. Народная тяга к искусству здесь выразилась в своеобразном «театральном» движении общественности и борьбе за создание своего театра, так как профессионального театра в городе до сих пор не существовало, если не считать выступление гастролирующих трупп. Многие театральные труппы, приезжавшие в Верхнеудинск, были гастролерами. Как правило, в репертуаре таких трупп преобладали дешёвые «кассовые» пьесы: фарсы, мелодрамы, псевдоисторические драмы, а их сценическое воплощение оставляло желать лучшего. Однако имели место и «гастроли столичных театральных коллективов, таких как «Синяя блуза», Театр Революции, Московский передвижной организационный синтетический театр Международного Красного Стадиона и Осовиахима СССР (Оргтеатр)» [7, с. 91]. В данной ситуации, характерной для всех регионов страны, перед театральными коллективами Советской России была поставлена задача: ориентироваться на рабочего зрителя, ставить пьесы о современности, пропагандировать новые идеи, влиять на рост самосознания и общей культуры людей. «В этих условиях театральное искусство, вырабатывая новые принципы изобразительности и принципы воздействия на зрителей, стремилось отразить мистическую ломку и политические бури в сознании простого народа» [8, с. 47].

Рождение профессионального театрального искусства Бурятии тесно связана с Московским передвижным организационным синтетическим театром Международного Красного Стадиона и Осовиахима СССР, или Оргтеатром. Его спектакли произвели огромное впечатление на публику, и Оргтеатру было предложено остаться в столице Бурят-Монгольской АССР. Творческий коллектив принял предложение остаться в Бурятии на зимние сезоны 1928-1933. 22 декабря 1928 года открылся первый театральный сезон спектаклем «Человек с портфелем». Этот день стал днём рождения Русского драматического театра Бурят-Монгольской АССР. Деятельность Оргтеатра имела историческое значение в становлении и развитии первого профессионального драматического театра в БурятМонгольской АССР. Театральный коллектив Оргтеатра заложил прочную основу театрального искусства, многоуровневую систему производства, потребления и создания духовных ценностей.

Дальнейшая история развития просветительской, художественной и театральной культуры Верхнеудинска (с 1934 года - Улан-Удэ) и Бурят-Монгольской АССР была связана с именем начальника управления зрелищных предприятий Наркомпроса А. В. Миронским, который способствовал не только пополнению труппы новыми талантливыми актёрами, но и формированию интересного классического и современного репертуара. У него была ясная и определённая эстетическая программа, он мечтал о театре высокой идейности и подлинной художественности, о театре, который покажет действительность в динамике, который в сложных полнокровных образах расскажет о становлении нового человека. На фоне бурных театральных манифестов тех лет эта программа оказалась живой и понастоящему плодотворной. Гражданственность, психологический реализм, жизненная достоверность - вот основные принципы творческой жизни коллектива Русского драматического театра того времени. Именно эти принципы стали для театра тем стержнем, который способствовал формированию нового культурного пространства советской Бурятии.

На протяжении всей своей 90-летней истории Государственный русский драматический театр имени Н. А. Бестужева, обретая контуры собственного лица, заботился о будущих поколениях, о молодёжи, о зрителях, памятуя, что без духовной пищи, эмоциональных потрясений и интеллектуальной информации, которые способен дать людям театр, нет полнокровной жизни. Эта работа всегда была очень важна для общества потому, что смена поколений представляет собой важнейший компонент поступательного развития человечества. Поколения не только сменяют друг друга, но и сосуществуют долгое время вместе, составляя неразрывную «цепь» эпохи. Если не обращать внимания на 
эту деятельность, то в сознании молодёжи образуется «вакуум», который может легко заполнить «катастрофа», что приведёт общество к потере исторических перспектив развития.

Государственный русский драматический театр им. Н. А. Бестужева в культурном пространстве республики выступает, по меньшей мере, в двух основных ипостасях. «Театр - Храм»- хранитель не только лучших традиций драматической психологической школы, но и мирового драматического наследия. Так же театр это - центр национальной культуры, средоточие духовных устремлений, пропагандист прославленного классического наследия. Как явление искусства, культуры, каждый театральный спектакль вписывается в определённые художественные, эстетические традиции, нормы и т. п. С этой точки зрения он воспринимается зрителями, воздействует на их сознание, служит средством познания мира и приобщения к художественной культуре. «Театр - Мастерская» - эксперимент, непрестанное совершенствование форм и идей, рождение авангардных методов создания спектакля, как продукта творческой деятельности драматургов, режиссёров, актёров, художников. Здесь идёт поиск своей уникальной системы культурного диалога между театром и зрителем, совмещение творческого и административного подходов, выстраивание репертуарной политики. В этом качестве театр может быть рассмотрен как один из элементов воспроизводства мирового драматургического наследия.

Значение культурного наследия, помогающего усвоить опыт мировой истории, очень велико для духовного роста и развития человечества, так как становление личности невозможно без знания традиций и опыта предков. Сохранение как материальных, так и нематериальных объектов наследия, их приумножение - важная задача каждого поколения. Поскольку театральная культура живой творческий процесс, связанный с живыми людьми, исторической обстановкой, общественными устремлениями, мы можем утверждать, что драматический театр, являясь объектом историко-культурного наследия, одновременно служит одним из основных элементов по сохранению мирового театрального наследия и по его воспроизводству.

\title{
Сиисок литературь
}

1. Шулепова, Э. А. Культурная среда исторического города: методология изучения и трансляция // Культурологический журнал. - 2011. - № 1. - URL: http://cr-journal.ru/rus/journals/59.html\&j_id\%3D6 (дата обращения: 28.02.2019).

2. Баева, Л. В. Сохранение культурного наследия как воплощение ценности традиции // Философия и общество. - 2012. - № 1. - С. 109-118.

3. Любичанковский, А. В. Анализ понятия «культурное наследие» // Вестник Оренбургского государственного университета. - 2006. - № 12. - С. 83.

4. Копсергенова, А. А. Культурное наследие: философские аспекты анализа : автореф. дисс. ... канд. филос. наук: 09.00.13 // DisserCat: науч. электрон. б-ка диссертаций и авторефератов. - 2019. - URL: https://www.dissercat.com/content/kulturnoe-nasledie-filosofskie-aspekty-analiza (дата обращения: 17.03.2019).

5. Манзырева, Е. С. Художественная культура городов Восточной Сибири (XIX - начало XX вв.) : [моногр.]. - Улан-Удэ : ВСГАКИ, 2014. - 127 с.

6. Дележа, Е. М. Роль политических ссыльных в развитии театрального дела в Забайкалье // Бурятия XVII - начала XX в. Экономика и социально-культурные процессы : сб. науч. тр. - Новосибирск : Наука : Сиб. отд-ние, 1989. - С. 160-176.

7. Амгаланова, М. В. Взаимодействие культур в сфере художественного творчества (на примере бурятской и монгольской драматургии 1920-1940-х гг.) : моногр.-Улан-Удэ : Изд.-полигр. Комплекс ФГБОУ ВСГАКИ, 2008. - $151 \mathrm{c}$.

8. Амгаланова, М. В. Историко-культурологический анализ феномена репрессированной культуры (на материалах литературы Бурятии 1920-х годов) : [науч. изд-е].-Улан-Удэ : Изд.-полигр. Комплекс ФГБОУ ВСГАКИ, 2017. - 207 с.

Viktoriia V. Nekrashevich East-Siberian State Institute of Culture (Ulan-Ude, Russia) vinek17@mail.ru

\section{DRAMA THEATRE AS A PART OF BURYATIA REPUBLIC'S HISTORICAL AND CULTURAL HERITAGE}

\begin{abstract}
The article briefly reviews history of amateur theatrical activities and professional dramatic art in PreRevolutionary, Soviet, Post-Soviet Buryatia. The specifics of scientific understanding of theatrical art heritage as historical and cultural phenomenon is disclosed. Author points out on constitutive role of artistic and aesthetic traditions of dramatic art towards regional cultural life through the example of Nikolay Bestuzhev State Russian Dramatic Theatre, which was the first professional theatre of Buryatia (established in 1928).
\end{abstract}


Keywords: regional cultural process, intangible historical and cultural heritage, cultural space of a region, art of theatre, dramatic theatre, conservation of theatric heritage, reproduction of artistic culture, Nikolay Bestuzhev State Russian Dramatic Theatre, Buryatia.

УДК 391(571.17)=512.1:069.122

DOI: 10.32340/2414-9101-2019-4-19-22

\author{
О. Г. Рубицова \\ Этноэкологический музей-заповедник «Тюльберский городок» \\ (д. Старочервово Кемеровской области, Россия) \\ oxanaenot1985@yandex.ru
}

\title{
АКТУАЛИЗАЦИЯ ТРАДИЦИОННОЙ ТЕХНОЛОГИИ ТКАНЬЯ ТЕЛЕУТСКИХ ПОЯСОВ В МУЗЕЙНОЙ ДЕЯТЕЛЬНОСТИ
}

Аннотация. Представлено описание воссозданной в условиях музейного учреждения технологии ручного изготовления пояса «кур» - элемента костюмного комплекса бачатских телеутов Кемеровской области (Южная Сибирь, Россия). Автор относит технологию тканья телеутских поясов, игравших роль оберега, к числу несущих значимую этнографическую информацию объектов нематериального историко-культурного наследия тюркоязычного коренного малочисленного народа. Охарактеризован опыт работы музеев Кемеровской области по организации культурно-образовательных программ, включающих различные формы публичной презентации оригинальной технологии изготовления телеутских поясов.

Ключевые слова: бачатские телеуты, тюркоязычные коренные малочисленные народы Южной Сибири, народы Притомья, народный костюм тюркоязычных народов Южной Сибири, пояс, технология изготовления (тканья) пояса, музеефикация техники ручного ткачества, нематериальное историко-культурное наследие, актуализащия объектов нематериального культурного наследия в условиях музея.

В условиях глобализации объекты этнокультурного наследия утрачиваются в среде бытования. Особенно это касается нематериального наследия, к которому относятся традиционные технологии, в том числе и изготовления пояса как обязательного атрибута в одежде коренных народов Притомья.

Актуальность вопросов сохранения нематериального наследия подтверждается вниманием к нему Всемирной организации ЮНЕСКО [1], а также документами по сохранению «неосязаемого» наследия на уровне государственной политики России. Однако специфические свойства традиции требуют не только её консервации, но и включения в современную среду, актуализацию. Приоритетным направлением актуализации культурного наследия является музеефикация [2]. Данный процесс может быть реализован в пространстве современного музея, для чего необходимо определение методической основы музеефикации технологических процессов, что на сегодняшний день разработано недостаточно. Существует актуальная необходимость обоснования методов, принципов, форм музеефикации технологий традиционного производства в рамках музейной деятельности.

В среде бытования уникальная технология тканья поясов, которая является маркером культуры бачатских телеутов, почти полностью утрачена. Данный объект нематериального наследия презентуется исключительно на базе социокультурных институтов: домов культуры, историкоэтнографического музея «Чолкой».

Пояс являлся характерным элементом традиционного костюма коренных малочисленных народов Притомья, чей костюмный комплекс набором элементов сходен с таковым у целого ряда тюркоязычных народов Южной Сибири. Он включал рубаху, халат, штаны, головной убор и обувь. Рубаха и халат подпоясывалась поясом «кур», который у телеутов изготавливался в технике ручного ткачества.

Ткачество у бачатских телеутов являлось женским домашним ремеслом и распространялось только на пояса, возможно, потому, что этот предмет одежды выполнял отчётливо выраженную функцию оберега: пояс образовывал вокруг тела человека замкнутую окружность [3].

В среде бытования тканье у телеутов сохранялось практически до середины XX в. Осуществлялось ткачество двумя способами: на ткацком станке и без него. На ткацкий станок в виде узкой длинной лавки с опорами повдоль натягивались нити основы. Они были преимущественно из гарусных, 